\title{
Ледниковые отложения камового холма в Экостровском проливе, озеро Имандра
}

\author{
Вашков А.А., Носова О.Ю., Корсакова О.П., Колька В.В., Толстобров Д.С. \\ Геологический институт КНЦ РАН, Anamumbl,vashkov@geoksc.apatity.ru
}

\begin{abstract}
Аннотация. Полевыми работами в 2019 году установлено, что холм острова Могильный в Экостровском проливе озера Имандра является камовым. Он построен горизонтальнослоистыми флювиогляциальными аккумуляциями с покрышкой из абляционного тилла. Петрографический состав абляционного тилла указывает на формирование холма в зоне действия лопасти беломорского ледникового потока.
\end{abstract}

Ключевые слова: Кольский полуостров, кам, флювиогляциальные отложения, тилл, петрография.

\section{Glacial deposits of a kame hill in the Ekostrovskiy Strait, the Imandra Lake}

\author{
Vashkov A.A., Nosova O.Yu., Korsakova O.P., Kolka V.V., Tolstobrov D.S. \\ Geological Institute of the Kola Science Centre of RAS, Apatity,vashkov@geoksc.apatity.ru
}

\begin{abstract}
The field work in 2019 established that the hill of the Island of Mogilny in the Ecostrovsky Strait of Lake Imandra is kame. It is built with horizontally layered fluvioglacial accumulations with an ablation till cover. The petrographic composition of the ablation till indicates the formation of a hill in the zone of action of the Ecostrovskaya lobe of the White Sea glacial stream.
\end{abstract}

Key words: Kola Peninsula, Kame, glaciofluvial deposits, till, petrography.

В ходе полевых работ 2019 г. в проливе Экостровский, между двумя частями озера Имандра (Большой и Экостровской) было установлено, что находящийся в проливе остров Могильный является камовым холмом. Остров вытянут на 0.38 км с запада на восток при ширине 0.26 км. В 1970-ых годах XX в. был соединен с восточным берегом пролива насыпью автомобильной дороги, которая сейчас пересекает остров в его южной части. В рельефе остров выражен в виде овального холма относительной высотой до 18 м. Наивысшая точка холма расположена в северо-западной части. В районе наивысшей точки холма его строение вскрыто береговым уступом оз. Имандра высотой до 10-16 м.

На существующих геологических картах остров находится в зоне распространения покрова базального тилла осташковского горизонта, выраженного в этой части Кольского региона повсеместно (Семенова и др., 2008; Геологическая карта..., 2012). По одному из предположений на линии острова Могильный фиксируется краевая зона последнего оледенения фазы Сальпауселькя I, ориентированная субширотно (Геологическая карта..., 2012). Другое предположение (Евзеров, Николаева, 2000) указывает на формирование района острова во внешней полосе одного из поясов маргинальных образований, который ориентирован здесь согласно береговой линии котловины оз. Имандра, вокруг Хибинского массива.

Исследование проводилось при помощи комплекса геологических, структурных, геоморфологических и петрографических методов. В береговом уступе были произведены две расчистки: вы-

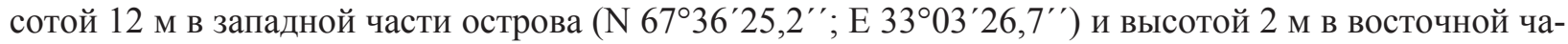

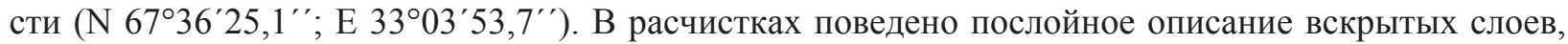
определение цвета, структуры и текстуры осадков. Из флювиогляциальных осадков произведен отбор проб на OSL-датирование. Структурный метод исследований ледниковых отложений заключался в определении углов падения слоистости, отдельно в толще тилла измерялись азимуты и углы падения длинных осей галек и валунов. Из слоя тилла отобраны пробы на определение петрографического состава гравийной и галечной фракций в объеме (12 литров) $20=25$ кг. На поверхности холма в 10 м от расчистки в западной части острова с площади $5 \times 5$ м произведен отбор валунной фракции для последующего определения её петрографического состава. При помощи геоморфологиче- 
ских методов были построены гипсометрические профиля через холм, выявлены основные морфометрические показатели холма.

В результате проведенных работ в строении западной части холма установлен тилл с маломощной песчаной покрышкой (рис. 1, I, II, слои 1, 2). Тилл сложен зеленовато-серым песком разнозернистым, преимущественно мелкозернистым, грубым, несортированным, пылеватым, с гравием, галькой, валунами. Толща тилла без видимой слоистости. Ниже валунов и крупной гальки отмечаются прослойки и линзы песка крупнозернистого светло-серого толщиной до 1 см, подобный материал образует и своеобразную «плёнку» вокруг валунов и галек. В тилле произведен замер ориентировки длинных осей галек (рис. 1, диаграмма А). Мощность тилла в разрезе не превышает 1.1-1.3 м.

Ниже залегает пачка флювиогляциальных аккумуляций общей мощностью свыше 11 м (рис. 1, I-IV, слои 3-10). Они представлены переслаиванием песчано-гравийной смеси с галькой, валунами, песков разнозернистых с гравием, песков мелкозернистых однородных. В интервалах 2.9-4.7 и 10.8-11.5 м и от поверхности отмечаются прослои песков тонкозернистых с тонкими прослоями алевритов, в интервале 11.2-11.5 м эти осадки обводнены (согласно урезу воды в озере). В отложениях наблюдается несколько типов слоистости: параллельная, перекрестная косая, реже однородная косая слоистость (рис. 1, диаграмма В). В нижней части разреза отмечаются отдельные сбросы с амплитудой смещения слоистости до 12 см (рис. 1, I, IV, слой 9). Отложения слоев 3, 4 и 9 были опробованы на глубинах 1.3, 2 и 10.3 м соответственно на OSL-датирование (образцы в работе).

Подобное строение было вскрыто в расчистке 2 в восточной части острова Могильный (рис. 1, I, V). Пачка тилла здесь имеет общую мощность до 1 м. Подошва тилла неровная. Отмечается общее падение подошвы слоя по азимуту $355^{\circ}$ под углом $14^{\circ}$. Ниже вскрыты флювиогляциальные пески мелко-, среднезернистые светло-серого цвета, с интервала 1.8 м от поверхности с выраженной слоистостью. Верхняя часть флювиогляциальной пачки деформирована, дислокации наблюдаются ниже участков внедрения в слой тиллов. Нарушения сопровождаются также небольшими сбросами с амплитудой смещения слоистости до $1.5 \mathrm{~cm}$.

Из приведенных выше материалов видно, что холм острова Могильный выражен в современном рельефе за счет толщи флювиогляциальных отложений различной размерности и степени сортировки. Субгоризонтальные прослойки глинистых песков свидетельствуют о присутствии во вскрытой толще некоторого количества лимногляциальных осадков. Вскрытые осадки относятся нами к камовой фации на основании следующих фактов:

- отсутствие мощных толщ флювиогляциального материала с углами падения свыше $15^{\circ}$;

- субгоризонтальный характер слоистости, в том числе границ между слоями;

- присутствие в толще осадков лимногляциального генезиса;

- наличие сбросов, что указывает на деформацию материала при таянии мертвого льда;

- морфология формы рельефа в виде компактного куполообразного холма.

Структура и цвет ледниковых отложений слоя 2, наличие тонких линз и прослойков крупнозернистого песка вокруг крупных обломков в целом характерны для базальных тиллов региона (Семенова, 2004; Евзеров, 2017). Выявлена упорядоченность обломочного материала, отмеченная в обоих расчистках с похожим расположением максимумов распределения падения линейных элементов $\left(85-305^{\circ}\right.$ в расчистке $1,90-300^{\circ}$ в расчистке 2 , рис. 1 , диаграммы A, С ). Однако в этом слое отсутствуют сланцеватая или плитчатая текстура, также обычно присутствующая в базальных тиллах. Отсутствуют линзы, прослои с включением, затягиванием в слой тилла нижележащего материала, а подошва слоя не несет признаков активного гляциодинамического воздействия на нижележащие флювиогляциальные отложения. Ниже подошвы тилла наблюдаются только незначительные деформации в тонкозернистых песках в расчистке 2 . В петрографическом составе обломков валунной фракций тилла преобладают гнейсы, гранодиоро-гнейсы, плагиограниты принесенные из районов котловины Экостровской Имандры и западнее неё (табл. 1, группа 1). В составе галечной и гравийной фракций наиболее распространены амфиболиты близлежащих с районом Экостровского пролива массивов, в том числе на холмах г. Оспе и г. Могильная. Породы вулканогенно-осадочных толщ и нефелиновые сиениты отсутствуют. Невысоки в пробах содержания обломков пород из мас- 


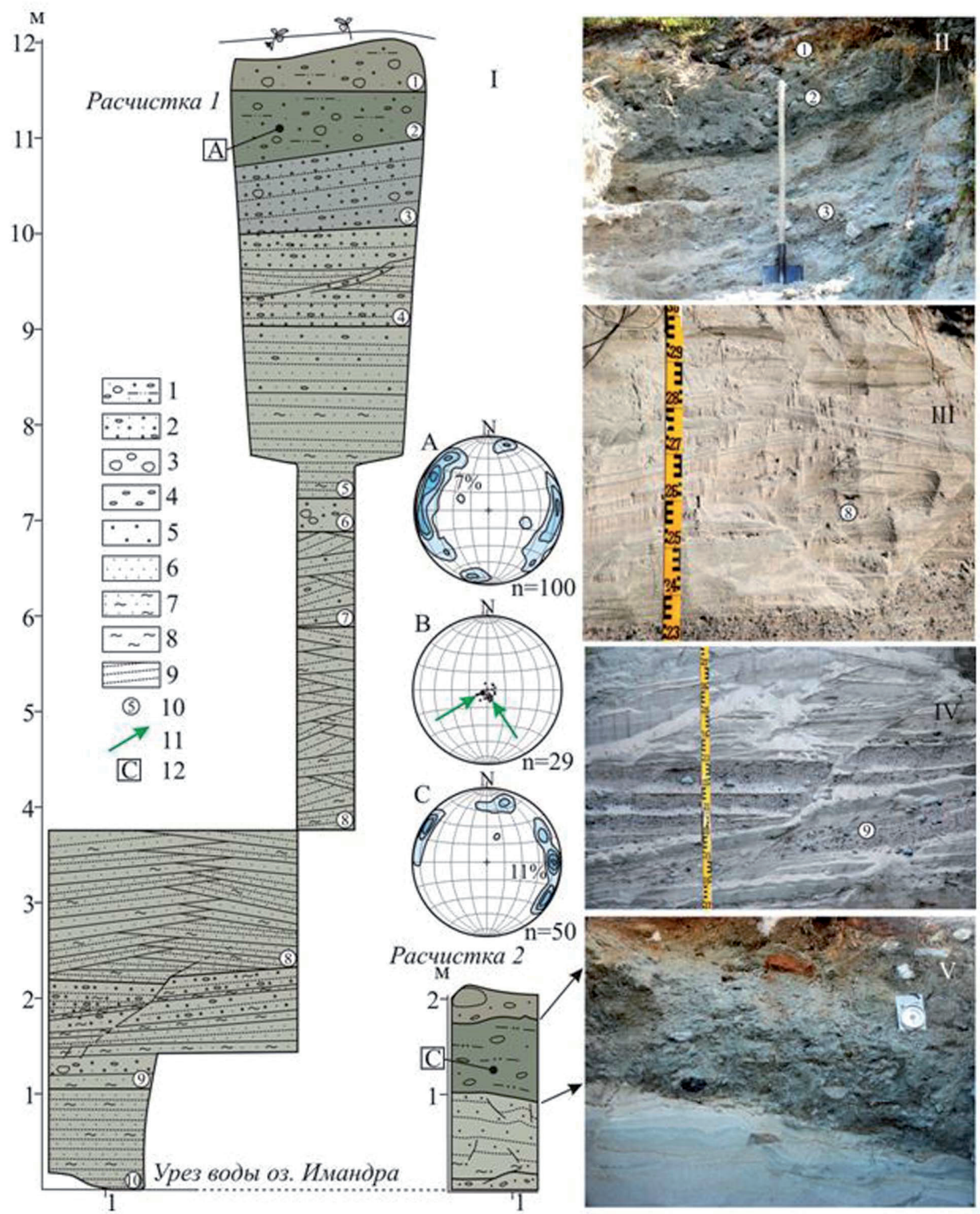

Рис. 1. Строение камовых аккумуляций острова Могильный в разрезе (I), фрагменты структуры тиллов (II, V) и флювиогляциальных осадков на фото (II-V): 1 - тилл; 2 - песчано-гравийно-галечная смесь; 3 - валуны; 4 - галька; 5 - гравий; 6 - песок; 7 - песок с алевритом; 8 - алеврит; 9 - внутренняя слоистость; 10 - номера слоёв на разрезе и фото; 11 - главные направления потоков талых ледниковых вод при формировании слоев 3-10 (на структурной диаграмме В); 12 - места замеров линейных элементов валунов и гальки (соответствуют номерам диаграмм). Структурные диаграммы построены на нижней полусфере сетки Шмидта.

Fig. 1 Kame deposits of the Mogilny Island in section (I), fragments of till fabric (II, V) and fluvioglacial deposits in the photo (II - V): 1 - till; 2 - sand-gravel-pebble mixture; 3 - boulders; 4 - pebbles; 5 - gravel; 6 - sand; 7 - silty sand; 8 -silt; 9 - inner lamination; 10 - layer numbers in the section and in the photos; 11 - the main flow direction of glacial melt water during formation of layers 3-10 (on the fabric diagram B); 12 - places of measurements of linear elements of boulders and pebbles (correspond to diagram numbers). The fabric diagrams are plotted on the lower hemisphere of the Schmidt net. 
сивов Главного хребта (габброиды гр. 2.3-2.5, табл. 1). Полученный петрографический состав грубообломочных фракций в целом характерен провинции Экостровской - Бабинской Имандры со значительным участием местного обломочного материала, слагающего поверхность кристаллического фундамента в радиусе 1-10 км от пункта опробования. По петрографическому составу тилл из пролива Экостровский хорошо отличим от базального тилла моренной равнины в районе г. Апатиты и п. Коашва (табл. 1, колонки II и III).

Таблица 1. Петрографический состав валунной, галечной и гравийной фракций абляционного тилла в разрезе острова Могильный.

Table 1. Petrographic composition of bolder, pebble, and gravel fractions of the ablation till in the section of the Mogilny Island.

\begin{tabular}{|c|c|c|c|c|c|c|c|c|}
\hline \multirow[t]{2}{*}{ № } & \multirow{2}{*}{ Группы пород } & \multirow{2}{*}{$\begin{array}{c}\text { Валуны } \\
>100 \text { мм } \\
\text { I }\end{array}$} & \multicolumn{3}{|c|}{$\begin{array}{c}\text { Галька } \\
10-100 \text { мм }\end{array}$} & \multicolumn{3}{|c|}{$\begin{array}{l}\text { Гравий } \\
\text { 5-10 мм }\end{array}$} \\
\hline & & & I & II & III & I & II & III \\
\hline 1 & $\begin{array}{l}\text { Гнейсы биотитовые, амфибол-биотитовые, } \\
\text { гранодиорито-гнейсы }\end{array}$ & 67.0 & 37.5 & 32.5 & 34.7 & 40.5 & 36.1 & 35.3 \\
\hline 2 & Основные породы, в т. ч.: & & & & & & & \\
\hline 2.1 & Амфиболиты ср/3 и м/3 & 27.6 & 45.3 & 9.5 & 8.9 & 46.2 & 9.6 & 8.3 \\
\hline 2.2 & габброиды ср/з актинолитизированные & 0.3 & 2.0 & 5.2 & 6.6 & - & 10.2 & 5.7 \\
\hline 2.3 & габбро, габбро-анортозиты ср-кр/з & - & - & - & 1.1 & 0.3 & 0.2 & - \\
\hline 2.4 & $\begin{array}{l}\text { габбро-милониты и гранат-амфибол- } \\
\text { плагиоклазовые породы по габброидам }\end{array}$ & 0.6 & 1.0 & 1.0 & 2.0 & 2.3 & 0.9 & 2.4 \\
\hline 2.5 & $\begin{array}{l}\text { ср- и м/3 габбро, нориты, габбро-нориты, } \\
\text { пироксениты }\end{array}$ & 0.3 & 1.8 & - & 0.9 & 0.8 & 0.2 & 0.5 \\
\hline 3 & Перидотиты, оливиниты & 0.3 & - & - & - & - & - & 0.1 \\
\hline 4 & Породы вулканогенно-осадочных толщ & - & - & 44.6 & 31.2 & 0.2 & 31.3 & 25.0 \\
\hline 5 & Нефелиновые и щелочные сиениты & - & - & - & 5.2 & - & 0.2 & 11.2 \\
\hline 6 & Жильные щелочные, лампрофиры, пикриты & 0.3 & 1.0 & 1.0 & - & 0.5 & 0.7 & 0.4 \\
\hline 7 & Фойдолиты & - & - & - & 1.4 & - & - & 0.9 \\
\hline 8 & Граниты розовые ср/з (гранит-мигматиты) & 3.4 & 10.9 & 4.6 & 6.9 & 8.6 & 8.3 & 9.5 \\
\hline 9 & Кварц* & 0.3 & 0.5 & 1.6 & 0.9 & 0.3 & 2.1 & 0.8 \\
\hline 10 & Полевые шпаты* & - & - & - & 0.3 & 0.2 & 0.2 & 0.1 \\
\hline
\end{tabular}

Примечание: I - остров Могильный; II - г. Огородная; III - Коашва. -* группы кварца и полевых шпатов рассмотрены вместе с горными породами, так как являются мономинеральными обломками неопределимых разрушенных горных пород.

Тилл слоя 2 может быть отнесен к базальным тиллам протаивания фации ареальной стагнации (Каплянская, Тарногардский, 1993). Принимая такой факт, камовые аккумуляции острова Могильный стоит, в свою очередь, относить к интрагляциальным, или так называемым, сложным камам (Раукас, Конт, 1978).

Таким образом, исследования в Экостровском проливе позволили установить новое местоположение камовых аккумуляций в Кольском регионе. Кам приурочен к северной периферии активной лопасти последнего ледникового покрова в котловине Экостровской Имандры, у её сочленения с участком развития малоактивного льда в котловине Большой Имандры. Между этими участками ледникового покрова, опираясь в том числе на поднятия ледникового ложа, проходила зона развития полостей и трещин в структуре ледника, что предопределило размещение здесь интрагляциальных флювиогляциальных аккумуляций.

Полученные результаты имеют большое значение для палеогеографических реконструкций позднего плейстоцена региона, могут быть использованы в природоохранных мероприятиях. Пони- 
мание условий размещения камовых аккумуляций в центральной части Кольского региона также может позволить определить поисковые критерии для месторождений строительных песков.

\section{Благодарность}

Авторы благодарят А.Д. Коваленко, Е.А. Овсюкова, В.М. Мымрина за помощь в проведении полевых работ.

Работа выполнена по теме НИР 0226-2019-0054 лаборатории № 43 Геологического института КНЦ РАН при поддержке гранта РФФИ 18-05-60125 Арктика.

\section{Литература}

1. Государственная геологическая карта Российской Федерации. Масштаб 1: 1000000 (третье поколение). Серия Балтийская. Лист Q-(35), 36 (Апатиты). Объяснительная записка / Гл. ред. Ю.Б. Богданов. СПб.: Картографическая фабрика ВСЕГЕИ. 2012. 456 с.

2. Евзеров В.Я. Литология морены поздневалдайского оледенения западной части Кольского полуострова // Вестник Мурманского государственного технического университета. 2017. Т. 20. № 1-1. С. 48-59. DOI: $10.21443 / 1560-9278-2017-20-1 / 1-48-59$.

3. Евзеров В.Я., Николаева С.Б. Пояса краевых образований Кольского региона // Геоморфология. 2000. № 1. С. 61-73.

4. Каплянская Ф.А., Тарноградский В.Д. Гляциальная геология: Методическое пособие по изучению ледниковых образований при геологической съемке крупного масштаба. СПб: Недра. 1993. 328 с.

5. Раукас А.В., Конт А.Р. Вопросы формирования и классификации камов // Строение и формирование камов. Таллин. 1978. С. 5-9.

6. Семенова Л.Р. Ледниковая геология Кольского полуострова (поздний плейстоцен) // Автореферат диссертации на соискание ученой степени кандидата геолого-минералогических наук по специальности 25.00 .01 - Общая и региональная геология. СПб: ВСЕГЕИ. 2004. 25 с.

7. Семенова Л.Р., Руденко Е.Д., Лукьянова Н.В. Геологическая карта четвертичных отложений, лист R-36-XXXIII, XXXIV (Апатиты), под ред. Заррина Е.П., тех. ред. Радченко С.А. СПб: картографическая фабрика ВСЕГЕИ. 2008. 